\title{
Research Paper: Investigating the Relationship of Visual Treatment and Rehabilitation With the Quality of Life and Visual Status in Children With Diagnosed Amblyopia
}

\author{
Seyedeh Fatemeh Norashrafodin ${ }^{1}$, Roshanak Vameghi ${ }^{*}$, Nikta Hatamizadeh ${ }^{1}$, Enayatollah Bakhshi $^{3}$, Farideh Yaghmaei $^{4}$ \\ 1. Department of Rehabilitation Management, University of Social Welfare and Rehabilitation Sciences, Tehran, Iran. \\ 2. Pediatric Neurorehabilitation Research Center, University of Social Welfare and Rehabilitation Sciences, Tehran, Iran. \\ 3. Department of Biostatistics, University of Social Welfare and Rehabilitation Sciences, Tehran, Iran. \\ 4. Department of Nursing, Faculty of Nursing \& Midwifery, Zanjan Branch, Islamic Azad University, Zanjan, Iran.
}

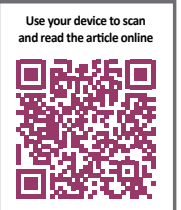

ditation: Norashrafodin SF, Vameghi R, Hatamizadeh N, Bakhshi E, Yaghmaei F. Investigating the Relationship of Visual Treatment and Rehabilitation With the Quality of Life and Visual Status in Children With Diagnosed Amblyopia. Iranian Rehabilitation Journal. 2017; 15(2):155-164. https://doi.org/10.18869/NRIP.IRJ.15.2.155

: https://doi.org/10.18869/NRIP.IRJ.15.2.155

Article info:

Received: 16 Dec. 2016

Accepted: 27 Mar. 2017

\section{A B S TRACT}

Objectives: To assess the relationship between visual rehabilitation with the quality of life and visual status in children who had been diagnosed with amblyopia in the national amblyopia screening program.

Methods: Information was gathered from optometric centers in the cities of Nowshahr, Chalus, and Kelardasht, or in case it was not available, from parents of participating children. The KINDL Health-Related Quality of Life Questionnaire for Children was also completed by the children. Children were examined regarding visual acuity, stereopsis, strabismus, and refractive errors. Statistical tests such as one way ANOVA and Pearson correlation coefficient were used via SPSS software version 22.

Results: Overall, the researchers obtained the records of 90 children with amblyopia, of which 76 were included in the study based on the inclusion criteria. The amblyopic children who did not have an early and timely start of treatment aid and did not complete treatment were the most prevalent group (38.2\%). The lowest frequency $(13.2 \%)$ pertained to those who did not have a timely start of treatment but experienced a completed treatment process. The highest proportion of children with entirely uncorrected amblyopia was those who had a timely start of treatment but did not complete the treatment. The majority of amblyopic children who had a completely corrected amblyopia had strictly acted in accordance with their therapist's prescription. In contrast, the majority of those children whose amblyopia was left completely untreated had not acted in accordance with the therapist's prescription. The children who had started treatment early but had not completed it obtained the lowest score on quality of life. The highest mean score was observed in the children who had completed their treatment process, either with or without an early start of the treatment.

Discussion: The completion of treatment seemed to be of higher importance in the correction of amblyopia and increased the quality of life than the early start of treatment. Therefore, the authorities and therapists are recommended to pay more attention to follow-ups for completion of the treatment process and its important impact on improving eyesight and children's quality of life.
Treatment, Rehabilitation, Amblyopia, Quality of life, Visual status, Screening
* Corresponding Author:

Roshanak Vameghi, PhD

Address: Pediatric Neurorehabilitation Research Center, University of Social Welfare and Rehabilitation Sciences, Tehran, Iran. Tel: +98 (21) 22180132

E-mail: r_vameghi@yahoo.com 


\section{Introduction}

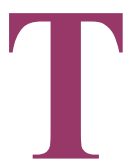

he eye is one of the most complex organs in the body, and about $85 \%$ of the information received from the surroundings comes from the eyes and the sense of vision. Hence, any damage to the eyes leads to the decline of the received information; in consequence, people's perception of the environment and quality of life are reduced [1]. Lazy eye (amblyopia) is the most common cause of low vision in children [2].

The risk factors that cause amblyopia include strabismus, refractive errors (especially anisometropia and high levels of hyperopia) and other causes of visual deprivation in the early years of life and also such factors as congenital ptosis and cataract [3]. The best age to identify and treat amblyopia has been recognized to be before the age of 5 years. Aging and evolution of the optic nerve reduce the response rate to treatment [4]. Untreated amblyopia results in irreversible blindness or low vision in one or both eyes, and consequently, it leads to psychosocial complications, such as learning disorders in children and lack of self-confidence in adulthood [2]. Worldwide, the prevalence of amblyopia in the preschool age group has been reported from 1 to $4 \%[5,6]$; however, this rate has been estimated about 2 to $5 \%$ in Iran [7].

In recent decades, "quality of life" has received more attention than ever and the importance of measuring the quality of life is increasing. The quality of life has been increasingly emphasized in the assessments related to the health area, as a means of evaluating the outcomes of care and health-based programs. The index of quality of life can demonstrate the extent of the effect on certain care and medical interventions in improving individuals' personal and social lives [8] and can make members of medical groups aware of the impact of care and help them develop more realistic plans in line with health care needs [9].

Visual screening is the usual method for the diagnosis of common vision disorders at young ages [10]. One of the most important goals of visual screening is the diagnosis of visual defects that can lead to amblyopia and subsequent treatment (primary prevention) and the early diagnosis and treatment of amblyopia (secondary prevention). Iran is one of the pioneers of implementing early childhood screening program for amblyopia and other vision disorders, and the early childhood screening program is one of the current programs of the health system. In this screening program, three levels of referral have been predicted. At the first level, the trained nursery and kindergarten caregivers and teachers carry out vision screening using the E-chart.

The suspected cases of visual disorders refer to optometrists so that more accurate diagnostic and therapeutic examinations can be done at the second level. If more specialized studies and examinations are required, the child will be referred to the third level, i.e., the ophthalmologist [11]. Monitoring of the services delivered at the first level is currently performed on the basis of a comprehensive plan and specific instructions and is recorded and documented in specific data sheets [11]. However, at the second and third levels of service provision, i.e., examination, diagnosis, and treatment by an optometrist or an ophthalmologist, unfortunately, there is no systematic program to track and monitor the process. In conclusion, there is no follow-up, and supervision is carried out in practice by a specified entity in the treatment and rehabilitation of these children after screening and early diagnosis. Thus, it is not clear how things proceed after the screening, are the objectives of the national program met and, thereby, what are the outcomes of such financial expenditures and human resources.

Therefore, the aim of this study was to evaluate the children diagnosed with amblyopia in the national screening program and to compare the children who had an early and timely start of the treatment and a completed treatment process, with those who had a late start of the treatment and an incomplete treatment, in terms of the effectiveness of the interventions on children's vision and quality of life.

\section{Methods}

This is a descriptive-analytical correlational study. After obtaining approval from the University of Social Welfare and Rehabilitation Sciences to carry out this study, the researchers obtained the information and documents of all 3 to 6 years old children who had been diagnosed with amblyopia in the national amblyopia screening program from the year 2009 to 2011 in the cities of Nowshahr, Chalus, and Kelardasht, and whose records were available in the optometric centers collaborating with the program. Then, the required preliminary information was extracted from the medical files available at these centers. The children eligible for participation in the study were identified based on the inclusion and exclusion criteria.

The inclusion criteria were: 1 . Availability at the time of carrying out the research, 2. Children and parents' consent to participate in the research, and 3. Being 8 to 
12 years old age at the time study was conducted. The exclusion criteria were: 1 . Withdrawal from the continuation of participation, 2. Gross disability or a diagnosed major illness, and 3. Incomplete medical records available at the optometric centers.

Total 90 children were recruited, out of which 76 were eligible to participate in this study. Families were contacted on the registered telephone numbers in the files, and necessary information regarding the research was given to the parents of the children and the appointment time for visiting them and their children in person, was fixed.

For all the children participating in this study, different forms and questionnaires were completed. The KINDL Health-Related Quality of Life Questionnaire for Children was filled out by the children. The content validity of the original version of the KINDL questionnaire has been determined by 20 experts, based on the Waltz and Bassel index. Its reliability has been determined both by calculating Cronbach's alpha for consistency measurement and by performing test-retest for stability, the result of which has been reported to be 0.84 and 0.80 , respectively [9].

It should be noted that the validity and reliability of the Persian version of the self-report KINDL Questionnaire for 8 to 12 years old children had been already assessed by Yaghmayi et al. in 2010 [9]. However, considering the target group of this study (children) who had experienced mild to severe rates of reduced visual acuity in one or both eyes and target group may even be experiencing it at the time of conducting the study some modifications were made on the "illness" subdomain of the questionnaire, accordingly. Then, with the collaboration of 15 experts, its face and content validity were assessed qualitatively and quantitatively (by the Lawshe's method). For reliability assessment, a test-retest correlation coefficient of 0.91 was obtained through a pilot study on 15 children, and finally, the Cronbach's alpha was determined to be 0.93 .

\section{Results}

As presented in Table 1, the 5 to 6 year-old age group (i.e., 5 years old to 5 years, 11 months and 28 days old) constituted the most frequent age group at the time of screening (38.2\%) while the lowest frequency $(17.1 \%)$ belonged to the 3 to 4 years old (i.e., 3 years old to 3 years, 11 months and 28 days old) age group.

As presented in Table 2, the amblyopic children who had neither an early start of treatment nor a completed treatment constituted the highest frequency $(38.2 \%)$. Although, the lowest frequency (13.2\%) belonged to the amblyopic children who did not have an early start of treatment but who experienced a completed treatment process.

As reported in Table 3, amblyopia in the children with both an early start of the treatment and a completed process of treatment was fully corrected and cured. Moreover, the majority $(90 \%)$ of the children without an early start, but with a completed treatment were cured and corrected completely. None of the children in the two mentioned groups were left with completely uncured and uncorrected amblyopia. Whereas, in children without a completed treatment process (whether with or without an early start of treatment), the rate of complete cure and correction of amblyopia was never higher than $27.6 \%$, and amblyopia in 27.6 and $33.3 \%$ of the two latter groups was left completely uncured and uncorrected.

The highest rate of completely cured and corrected amblyopia was observed in the children who had started treatment at the age of 3 to 4 years, and the highest prevalence of completely uncured and uncorrected amblyopia was observed in children who had started treatment at the age of 6 to 7 years (Table 4). Also, the highest rates of uncured and uncorrected amblyopia belonged to the children who had discontinued treatment from the age of 4 to 5 years old and 3 to 4 years old, respectively. In addition, no complete cure and correction were observed in the two latter groups.

The greatest difference between the mean visual acuity at the first visit to the optometrist and at the time of research belongs to children who have experienced both an early start and a completed treatment (Table 5). On the other hand, the lowest difference pertains to the children with an early start but an uncompleted treatment process.

The greatest mean score of quality of life in the physical, mental, self-confidence, and school domains, as well as the total quality of life, belonged to children with both an early start and a completed treatment process (Table 6). Also, the highest mean score of quality of life in the family, friends and disease domains belonged to children without an early start but with a completed treatment process. In fact, these two groups of children never stood lower than the other two groups of children who did not have a completed treatment process, regarding the total quality of life or any of its domains. Whereas the lowest mean scores for all domains and the total quality of life belonged to children, who had an early start of treatment but did not have a completed treatment process. 
Table 1. Some descriptive findings of the participants

\begin{tabular}{|c|c|c|c|}
\hline & Descriptive Findings & Number & Percent \\
\hline \multirow{2}{*}{ Sex } & Male & 37 & 48.7 \\
\hline & Female & 39 & 51.3 \\
\hline \multirow{2}{*}{$\begin{array}{l}\text { Amblyopia in terms of unilateral } \\
\text { or bilateral }\end{array}$} & Unilateral & 53 & 69.7 \\
\hline & Bilateral & 23 & 30.2 \\
\hline \multirow{4}{*}{ Amblyopia in terms of etiology } & Anisometropia & 49 & 64.5 \\
\hline & Ametropia & 22 & 28.9 \\
\hline & Strabismus & 3 & 3.9 \\
\hline & Visual deprivation & 2 & 2.6 \\
\hline \multirow{4}{*}{$\begin{array}{l}\text { Distribution of participants in } \\
\text { the study by age at the time of } \\
\text { initiation of treatment }\end{array}$} & From 3 years old to 3 years, 11 months and 28 days old & 13 & 17.1 \\
\hline & From 4 years old to 4 years, 11 months and 28 days old & 24 & 31.6 \\
\hline & From 5 years old to 5 years, 11 months and 28 days old & 29 & 38.2 \\
\hline & From 6 years old to 7 years, 11 months and 28 days old & 10 & 13.2 \\
\hline
\end{tabular}

The results of one-way ANOVA showed a significant difference between the groups. The results of the Bonferroni post hoc test showed that the mean score of the fourth group's quality of life was significantly different from that of the second and third groups. The highest mean score of quality of life totally and in all domains belonged to children whose amblyopia had been completely cured and corrected, while the lowest mean score of quality of life totally and in all domains belonged to the group whose amblyopia had not been treated at all (Table 7).

The group of children whose amblyopia were relatively cured and corrected stood in between the two other groups in all domains of quality of life. So, the better and more complete cure and correction of amblyopia, the higher the quality of life in all domains and totally. The results of the Bonferroni post hoc test showed that in the physical and friends domains of quality of life, the mean scores of the group who were not cured and corrected at all were significantly different from those of the other two groups. In the remainder of the domains of quality of life, the significant difference was due to differences between all three groups.

The results of the Pearson correlation test showed a significant relationship between the number of visits to the optometrist and all components of quality of life as well as the total quality of life, such that an increase in the

Table 2. Distribution of participants in terms of the four categories regarding starting time of treatment and completion of treatment

\begin{tabular}{|ccc|}
\hline Starting Time and Completion of Treatment & Frequency & Percent \\
\hline Children with both an early start of treatment ${ }^{*}$ and a completed treatment process & 21.1 \\
\hline Children with neither an early start of treatment nor a completed treatment process & 16 & 38.2 \\
\hline Children with an early start of treatment but an uncompleted treatment process & 21 & 27.6 \\
\hline Children without an early start of treatment but with a completed treatment process & 10 & 13.2 \\
\hline Total & $76 \quad$ Iranian Rehabilitation】ournal \\
\hline
\end{tabular}

*An early start of treatment means a start before the age of 5 years. ${ }^{* *}$ The completion of treatment means the patient's discharge declared and registered by the optometrist. 
Table 3. Degree of correction of amblyopia regarding categories regarding starting time of treatment and completion of treatment

\begin{tabular}{|c|c|c|c|}
\hline $\begin{array}{r}\text { The Degree of Cure and Correction } \\
\text { of Amblyopia }\end{array}$ & $\begin{array}{l}\text { Completely Cured and } \\
\text { Corrected }^{*}\end{array}$ & $\begin{array}{l}\text { Relative Cure and } \\
\text { Correction }\end{array}$ & $\begin{array}{l}\text { Not Cured and Cor- } \\
\text { rected at All }\end{array}$ \\
\hline $\begin{array}{l}\text { Starting Time and } \\
\text { Completion of Treatment }\end{array}$ & Number (Percent) & Number (Percent) & Number (Percent) \\
\hline $\begin{array}{l}\text { Children with both a timely start of treatment } \\
\text { and a completed treatment process }\end{array}$ & $16(100)$ & $0(0)$ & $0(0)$ \\
\hline $\begin{array}{l}\text { Children with neither a timely start of treatment } \\
\text { nor a completed treatment process }\end{array}$ & $8(27.6)$ & $13(44.8)$ & $8(27.6)$ \\
\hline $\begin{array}{l}\text { Children with a timely start of treatment but an } \\
\text { uncompleted treatment process }\end{array}$ & $2(9.5)$ & $12(57.1)$ & $7(33.3)$ \\
\hline $\begin{array}{l}\text { Children with an untimely start of treatment but } \\
\text { a completed treatment process }\end{array}$ & 9(90) & $1(10)$ & $0(0)$ \\
\hline Total & $35(46)$ & $26(34.2)$ & 15(19.7) \\
\hline
\end{tabular}

Iranian Rehabilitation Journal

"If at the studying time the visual acuity VA=10/10 of the amblyopic eye with maximum correction is , then amblyopia has been completely cured and corrected. ${ }^{*}$ If the visual acuity with maximum correction in the amblyopic eye at the time of research has increased compared to the visual acuity with maximum correction in the amblyopic eye at the first visit, relative cure and correction have occurred. ${ }^{* t *}$ If the difference between the visual acuity with maximum correction in the amblyopic eye at the first visit and at the time of research equals to zero (unchanged), has amblyopia has not been cured and corrected at all.

Table 4. Distribution of the degree of cure and correction of amblyopia in participating children in terms of the age of onset and age of discontinuation of treatment

\begin{tabular}{|c|c|c|c|c|}
\hline \multirow{2}{*}{\multicolumn{2}{|c|}{$\begin{array}{l}\text { The Degree of Cure and Correction } \\
\text { of Amblyopia }\end{array}$}} & \multirow{2}{*}{$\begin{array}{c}\begin{array}{c}\text { Completely Cured } \\
\text { and Corrected }\end{array} \\
\text { Number (Percent) }\end{array}$} & \multirow{2}{*}{$\begin{array}{c}\begin{array}{c}\text { Relative Cure and } \\
\text { Correction }\end{array} \\
\text { Number (Percent) }\end{array}$} & \multirow{2}{*}{$\begin{array}{c}\begin{array}{c}\text { Not Cured and } \\
\text { Corrected at All }\end{array} \\
\text { Number (Percent) }\end{array}$} \\
\hline & & & & \\
\hline \multirow{4}{*}{$\begin{array}{l}{ }^{*} \text { The age } \\
\text { of onset of } \\
\text { treatment }\end{array}$} & $\begin{array}{c}\text { From } 3 \text { years old to } 3 \text { years, } 11 \text { months and } \\
28 \text { days old ( } 3 \text { to } 4 \text { years old) }\end{array}$ & $7(53.8)$ & $5(38.5)$ & $1(7.7)$ \\
\hline & $\begin{array}{l}\text { From } 4 \text { years old to } 4 \text { years, } 11 \text { months and } \\
28 \text { days old ( } 4 \text { to } 5 \text { years old) }\end{array}$ & $11(45.8)$ & $7(29.2)$ & $6(25)$ \\
\hline & $\begin{array}{l}\text { From } 5 \text { years old to } 5 \text { years, } 11 \text { months and } \\
28 \text { days old ( } 5 \text { to } 6 \text { years old) }\end{array}$ & 15(51.7) & $9(31)$ & $5(17.2)$ \\
\hline & $\begin{array}{l}\text { From } 6 \text { years old to } 7 \text { years, } 11 \text { months and } \\
28 \text { days old ( } 6 \text { to } 7 \text { years old) }\end{array}$ & $2(20)$ & $5(50)$ & $3(30)$ \\
\hline \multirow{4}{*}{$\begin{array}{l}\text { **The age of } \\
\text { discontinua- } \\
\text { tion of treat- } \\
\text { ment }\end{array}$} & $\begin{array}{c}\text { From } 3 \text { years old to } 3 \text { years, } 11 \text { months and } \\
28 \text { days old ( } 3 \text { to } 4 \text { years old) }\end{array}$ & $0(0)$ & $2(66.7)$ & $1(33.3)$ \\
\hline & $\begin{array}{l}\text { From } 4 \text { years old to } 4 \text { years, } 11 \text { months and } \\
28 \text { days old ( } 4 \text { to } 5 \text { years old) }\end{array}$ & $0(0)$ & $6(50)$ & $6(50)$ \\
\hline & $\begin{array}{l}\text { From } 5 \text { years old to } 5 \text { years, } 11 \text { months and } \\
28 \text { days old ( } 5 \text { to } 6 \text { years old) }\end{array}$ & $6(31.6)$ & $8(42.1)$ & $5(26.3)$ \\
\hline & $\begin{array}{l}\text { From } 6 \text { years old to } 7 \text { years, } 11 \text { months and } \\
28 \text { days old ( } 6 \text { to } 7 \text { years old) }\end{array}$ & $4(26.7)$ & $8(53.3)$ & $3(20)$ \\
\hline
\end{tabular}

"The age of onset of treatment refers to the age at which children have started their treatment visits.

** The age of discontinuation of treatment refers to the age at which children have stopped their treatment visits without receiving any notice and discharge from the optometrists. 
Table 5. Mean difference in visual acuity with maximum correction in the amblyopic eye between first visit and the study time in terms of the four categories regarding starting time and completion of treatment

\begin{tabular}{|cc|}
\hline Starting Time and Completion of Treatment & $\begin{array}{c}\text { Mean Difference in Visual Acuity With } \\
\text { Maximum Correction in the Amblyopic Eye } \\
\text { Between First Visit and the Study Time }\end{array}$ \\
\hline Children with both a timely start of treatment and a completed treatment process & 0.43 \\
\hline Children with neither a timely start of treatment nor a completed treatment process & 0.21 \\
\hline Children with a timely start of treatment but an uncompleted treatment process & 0.13 \\
\hline Children with an untimely start of treatment but a completed treatment process & 0.39 \\
\hline Total & 0.29 \\
\hline
\end{tabular}

Table 6. Mean quality of life in different domains and totally in terms of the four categories regarding starting time and completion of treatment

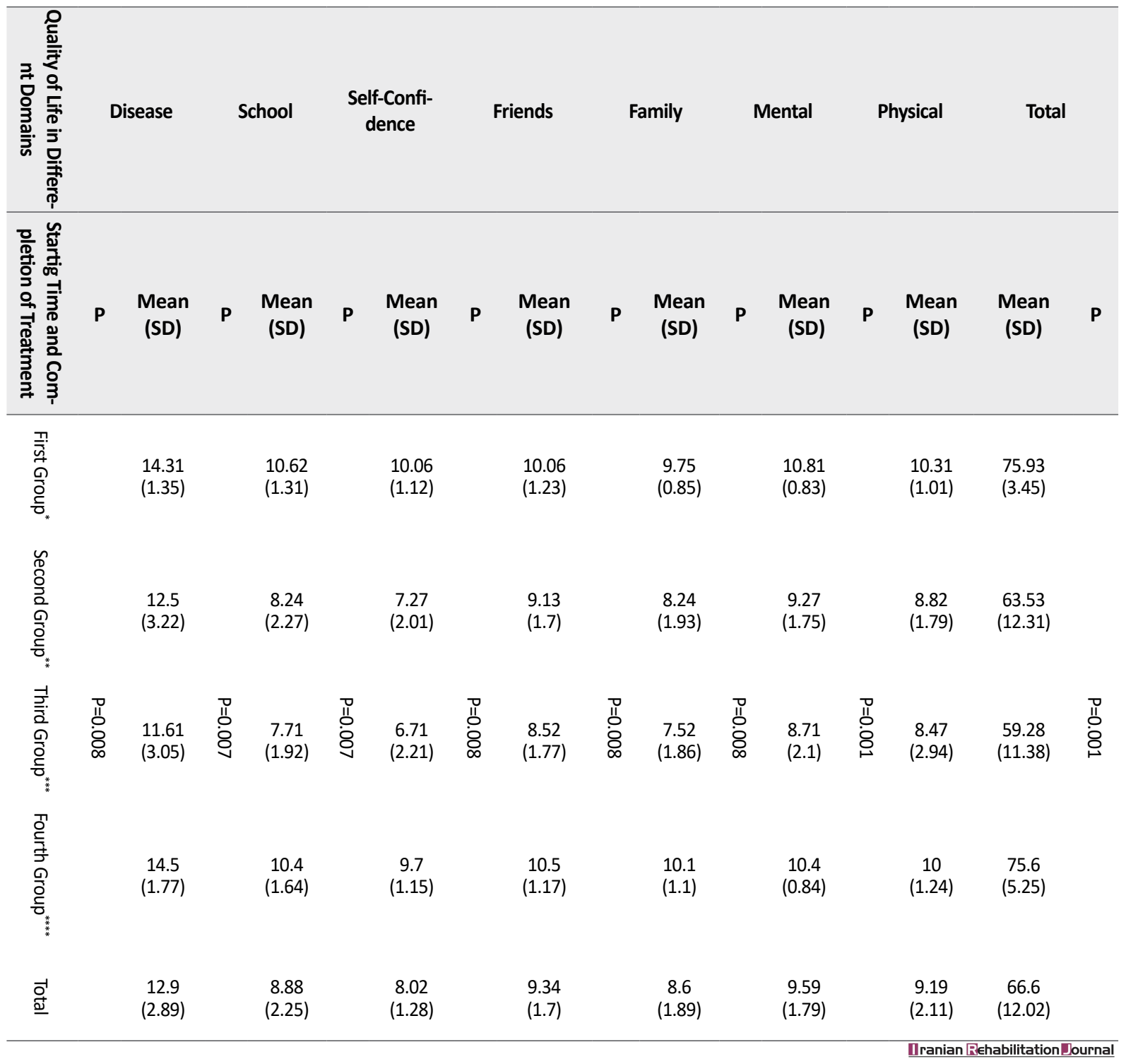

${ }^{*}$ Children with both a timely start of treatment and a completed treatment process. ${ }^{* *}$ Children with neither a timely start of treatment nor a completed treatment process. ${ }^{* * *}$ Children with a timely start of treatment but an uncompleted treatment process. ${ }^{* * *}$ Children with an untimely start of treatment but a completed treatment process. 
Table 7. Mean quality of life in different domains and totally in terms of the three categories regarding degree of cure and correction

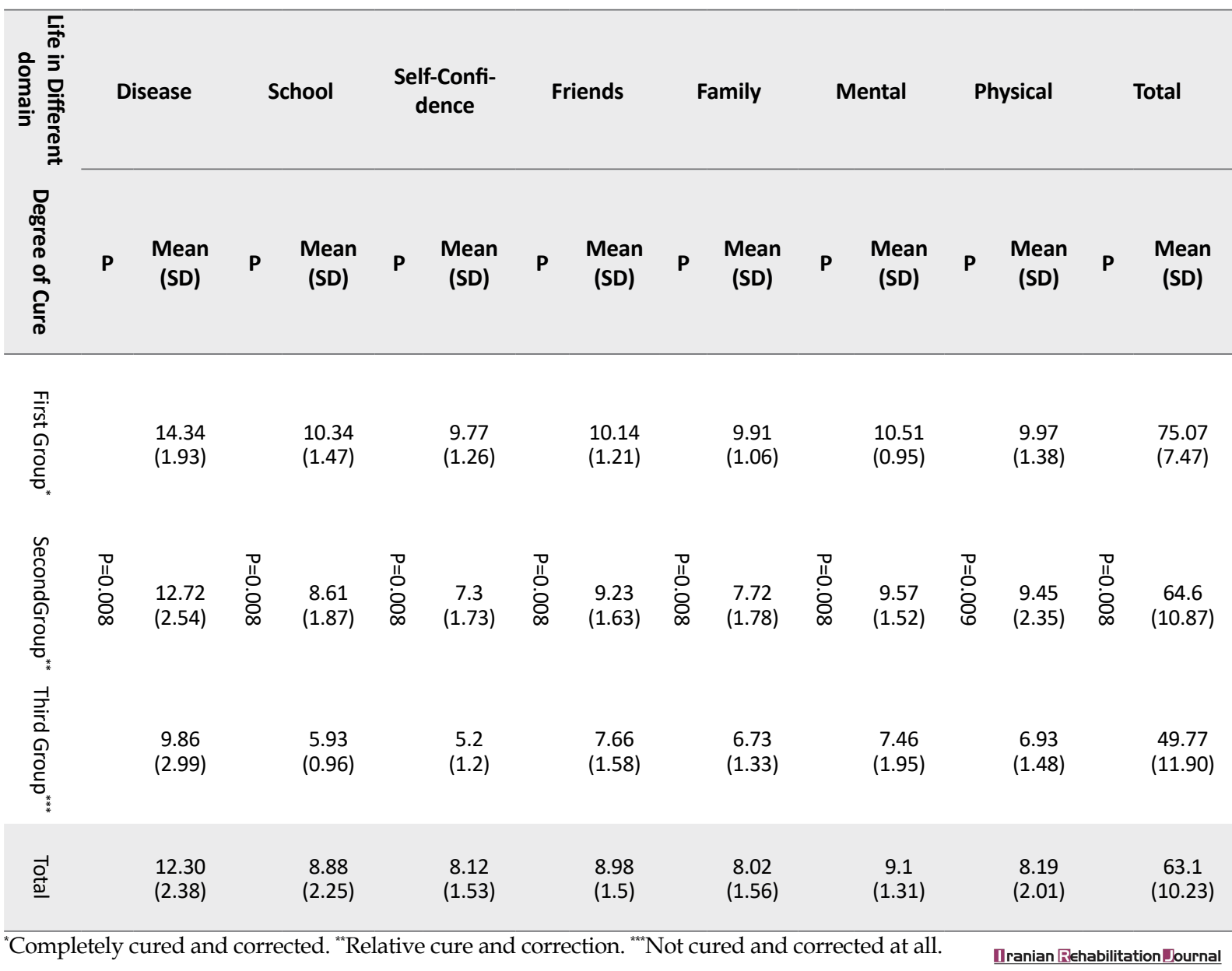

number of visits increased the quality of life score (Table 8). There is a significant relationship between amblyopic treatment and correction and quality of life. Finally, it is noteworthy that the relationship between gender and quality of life was insignificant.

\section{Discussion}

The results of this study showed that amblyopia in children with both an early start of the treatment and a completed process of treatment was fully corrected and cured and the majority (90\%) of children without an early start but with a completed treatment were also cured and corrected completely. None of the children in the two mentioned groups were left with completely uncured and uncorrected amblyopia. Whereas, in children without a completed treatment process (whether with or without an early start of treatment), the rate of complete cure and correction of amblyopia was never higher than one-third, and amblyopia in about one-third of the two latter groups were left completely uncured and uncorrected.
Furthermore, the highest mean score of quality of life totally and in all domains was observed in the children whose amblyopia had been completely cured and corrected while the lowest score of quality of life belonged to the group of children whose amblyopia had not been cured and corrected at all. Also, in all domains of quality of life, the lowest mean scores belonged to the group with an early start of treatment, but with an uncompleted process of treatment, whereas the highest mean scores were observed in the first and fourth groups of children with a completed process of treatment (whether with a start or without an early start of treatment).

On the whole, the results mentioned above suggest that the completion of the treatment has had an even more important role in the improvement of the quality of life as well as the cure and correction of amblyopia, than the early start of treatment. In other words, children with a completed process of treatment (whether with or without an early start of treatment) experienced the highest rate 
Table 8. Correlation of quality of life in all domains and totally with the number of visit

\begin{tabular}{|c|c|}
\hline Quality of Life in Different Domains & $\begin{array}{l}\text { Pearson Correlation of the Relationship Between Quality of } \\
\text { Life and the Number of Visits }\end{array}$ \\
\hline Total & $\begin{array}{l}{ }^{* *} 0.56 \\
\mathrm{P}=0.007\end{array}$ \\
\hline Physical & $\begin{array}{l}* * 0.38 \\
P=0.009\end{array}$ \\
\hline Mental & $\begin{array}{l}{ }^{* *} 0.37 \\
\mathrm{P}=0.009\end{array}$ \\
\hline Confidence & $\begin{array}{l}* * 0.59 \\
P=0.008\end{array}$ \\
\hline Family & $\begin{array}{l}{ }^{* *} 0.46 \\
\mathrm{P}=0.008\end{array}$ \\
\hline Friends & $\begin{array}{l}{ }^{* *} 0.41 \\
P=0.008\end{array}$ \\
\hline School & $\begin{array}{l}* * 0.57 \\
P=0.008\end{array}$ \\
\hline Disease & $\begin{array}{c}* * 0.33 \\
P=0.009\end{array}$ \\
\hline
\end{tabular}

of correction of amblyopia, as well as the highest rate of quality of life.

Hoseinian et al., reported that 58 parents $(88 \%)$ had been made aware of the importance of timely treatment. More than $90 \%$ of the files lacked the documents and information about awareness-raising, training, and guidance for obviating the treatment obstacles. One year following the treatment of visual acuity, $66.6 \%$ of the children were fully corrected, $10.6 \%$ of them were partially treated, and $22.8 \%$ of them experienced no alteration. The visual acuity of the children that were not under the follow-up process after the initial prescription had not been completely corrected [11]. The results obtained in the present study showed that in $46.1 \%$ of the children amblyopia had been completely cured and corrected, relatively corrected in $32.9 \%$, and not corrected at all in $30 \%$.

In a review by Carolyn et al. in 2006 reported that the early detection and treatment of amblyopia could help improve vision and to achieve other successful therapeutic outcomes. Moreover, it was found that no compelling evidence existed regarding the claim that treatment for children above 10 years of age can be useful [12]. This finding is in agreement with our results in the present study, that the early start of treatment has been shown to be important regarding treatment outcomes.

Sheikhi et al., showed that amblyopia treatment could lead to successful results even in elementary school ages. However, there was some debate over the amount and degree of the visual disorder [2]. This result is partly consistent with that of the present study in that a higher importance is attached to "completed treatment" than "the timely start of treatment". However, while most of the current studies on amblyopia and its treatment have addressed the importance of early detection and timely treatment, they have rarely paid attention to the serious and important role of continuous treatment follow-ups and the completion of the treatment process. One of the actual instances of this fact is the national amblyopia screening program that is implemented in Iran every year with high costs. This program pays high attention to the timely diagnosis of children's amblyopia and the timely start of treatment and does not assign much credit and resources to how the therapeutic follow-ups take place and to the completion of treatment.

Wen et al., reported that there was a significant association between general health-related quality of life and strabismus. However, no significant association was found between amblyopia and general health-related quality of life [13]. In the present study, the direct relationship between strabismus and quality of life was not investigated, but the children whose amblyopia had been completely left uncorrected experienced the lowest quality of life and the children whose amblyopia had been completely corrected experienced the highest quality of life totally and in all domains. This result is inconsistent with that of Wen et al.

Bogdănici et al., in 2015 carried out a study in Romania to assess changes in the quality of life of amblyopic children and their parents. For this purpose, an observational study was conducted in 44 patients who had referred to the Ophthalmology Clinic of Isperidone Hospital. The results showed that the patients who had started treatment at a younger age reached better outcomes and experienced higher levels of quality of life [14]. In the present study, the highest mean score of quality of life 
was found in the first and fourth groups of children who had experienced a completed process of treatment. In the present study, it was also revealed that the completion of treatment plays a greater role in improving the quality of life compared to the timely start of treatment.

In a study conducted by Eftekhar et al. it was reported that the relationship between visual acuity and quality of life was significant, where visually impaired and blind individuals showed the significantly reduced quality of life in the mobility domain, compared to the healthy controls [15]. In the present study, a significant relationship was obtained between visual acuity and quality of life, such that the highest degree of total quality of life and its different domains belonged to the group of children who had experienced a completely cured and corrected amblyopia compared to those who had been relatively cured or completely uncorrected.

\section{Conclusion}

In the present study, amblyopic children who were completely cured showed the highest mean score of quality of life in different dimensions. In contrast, the lowest mean score of quality of life belonged to the amblyopic children who had not been cured at all. In contrast, the lowest mean score of quality of life belonged to the amblyopic children who had not been cured at all.

Furthermore, the results of this study demonstrate that the completed process of treatment was just as important as the early start of treatment in the cure and correction of amblyopia, as well as in the improvement of the quality of life. Thus, it is suggested that relevant authorities and institutions should assign more or at least as much value and credit to the issue of completion of the treatment process than the issue of early onset of treatment and to devise appropriate mechanisms in the national program of amblyopia screening, for ensuring this issue. Also, it may be possible to help with the therapeutic follow-up required for the affected children using the continuation of this program in schools and the form of reassessment of amblyopia and its status in the school-aged children already diagnosed with amblyopia.

\section{Acknowledgements}

We acknowledge and appreciate the cooperation of all children, parents, and optometrists that helped us to conduct this study. This article is based on the M.S. thesis of Seyedeh Fatemeh Norashrafodin, named "Investigating the Relationship of Visual Treatment and Rehabilitation With the Quality of Life and Visual Status in Children
With Diagnosed Amblyopia in the National Amblyopia Screening Program from 2009 to 2011 in the Cities of Nowshahr, Chalus, and Kelardasht", from the Department of Rehabilitation Management of the University of Social Rehabilitation Sciences.

\section{Conflict of Interest}

The authors declared no conflicts of interest.

\section{References}

[1] Feridooni F, GhassemiBroumand M, Tabatabaeei SM. [The rate of satisfaction of low vision aids and quality of life in low visions referring to the red-crescent's low vision center of Tehran since 21 June 2011 till 21 June 2012 (Persian)]. Rehabilitation Medicine. 2013; 2(1):15-22. doi: 10.22037/r.m.v2i1.5246

[2] Sheikhi F, Ansari MR, Omidian J, Daneshgar F, Ghaderi E. [Amblyopia Therapy in Imam Khomeini hospital of Kermanshah (1998-2000) (Persian)]. Journal of Kermanshah University of Medical Sciences. 2006; 10(3):268-76.

[3] Rajavi ZH, Sabbaghi H, Shojaee A, Yaseri M, Moein HR, Akbariania $\mathrm{S}$, et al. [The prevalence of amblyopia among 7-12 year old primary school children of Tehran, Iran in 2013 (Persian)]. Scientific Journal of the Eye Bank of Iran. 2015; 20(2):117-30.

[4] Moseley M, Fielder AR. Amblyopia: A multidisciplinary approach. Boston: Butterwort -Heimann Co; 2002.

[5] United States Preventive Services Task Force. Screening for visual impairment in children younger than age 5 years: Recommendation statement. The Internet Journal of Ophthalmology and Visual Science. 2004; 3(1). doi: 10.5580/475

[6] Simons K. Amblyopia characterization, treatment, and prophylaxis. Survey of Ophthalmology. 2005; 50(2):123-66. doi: 10.1016/j.survophthal.2004.12.005

[7] Schimitzek T, Haase W. Efficiency of a video-autorefractometer used as a screening device for amblyogenic factors. Graefe's Archive for Clinical and Experimental Ophthalmology. 2002; 240(9):710-6. doi: 10.1007/s00417-002-0524-5

[8] Sarabandi A, Kamali M, Mobaraki H. [The relationship betweenimpairedvisualfunctionandquality of life of the blind Journal of Research in Rehabilitation Sciences (Persian)]. 2013 8(6):1015-23.

[9] Yaghmaei F, Aminzade S, Alavi Majd H, Rassouli M, Noorian M. [Translation and evaluation of psychometric properties of the KINDL Questionnaire (Persian)]. Payesh. 2012; 11(6):841-7.

[10] American Academy of Ophthalmology. Vision screening for infants and children 2013. California: American Academy of Ophthalmology; 2014

[11] Hosainian H, Hatamizade N, Vameghi R, Bakhshi E. [Process evaluation of therapy in children with amblyopia detected in amblyopia prevention program - 2012', Mashhad City 
(Persian)]. Journal of Rehabilitation Medicine. 2016; 5(1):10918.

[12] Wu C, Hunter DG. Amblyopia: Diagnostic and therapeutic options. American Journal of Ophthalmology. 2006; 141(1):175-84. doi: 10.1016/j.ajo.2005.07.060

[13] Wen G, McKean-Cowdin R, Varma R, Tarczy-Hornoch K Cotter SA, Borchert M, et al. General health-related quality of life in preschool children with strabismus or amblyopia. Ophthalmology. 2011; 118(3):574-80. doi: 10.1016/j.ophtha.2010.06.039

[14] Bogdănici ST, Costin D, Bogdănici CM. Quality of life for amblyopic children and their parents. Revista medico-chirurgicala a Societatii de Medici si Naturalisti din Iasi. 2015; 119(1):214-20. PMID: 25970969

[15] Eftekhar H, Nojoomi M, Koohpayeh-Zadeh J. A comparison of the quality of life among blind students and their sighted counterparts. Iranian Journal of Psychiatry and Clinical Psychology. 2002; 7(4):49-55. 